\title{
FRACTURE ENERGY METHOD IN PREDICTING CRACK SPACING OF REINFORCED CONCRETE STRUCTURES
}

\author{
JIA-JI WANG ${ }^{1}$, MU-XUAN TAO ${ }^{2, *}$ JIAN-GUO NIE $^{3}$ AND MENG ZHOU ${ }^{4}$ \\ ${ }^{1}$ Key Laboratory of Civil Engineering Safety and Durability of China Education Ministry, Department of \\ Civil Engineering, Tsinghua University, Beijing, China. \\ e-mail: wangjiaji tsinghua@163.com \\ 2,* State Key Laboratory of Structural Analysis for Industrial Equipment, Dalian University of Technology, \\ Dalian, China \\ Key Laboratory of Civil Engineering Safety and Durability of China Education Ministry, Department of \\ Civil Engineering, Tsinghua University, Beijing, China. \\ e-mail: taomuxuan@mail.tsinghua.edu.cn \\ ${ }^{3}$ Beijing Engineering Research Center of Steel and Concrete Composite Structures, Department of Civil \\ Engineering, Tsinghua University, Beijing, China \\ e-mail: niejg@mail.tsinghua.edu.cn \\ ${ }^{4}$ Key Laboratory of Civil Engineering Safety and Durability of China Education Ministry, Department of \\ Civil Engineering, Tsinghua University, Beijing, China \\ e-mail: zhoum07@mails.tsinghua.edu.cn
}

Key words: Crack spacing, Fracture energy criterion, Strength Criterion, Minimum potential energy principle with mixed variables

\begin{abstract}
The crack spacing of reinforced concrete structures has a major influence on structural performance. The fracture energy criterion of crack formation was employed to predict the crack spacing of concrete based on the linear elastic fracture mechanics. This method employs analytical derivation of three dimensional axisymmetric elastic mechanics problems. The simplified solution for a direct tension specimen with a single rebar at the center is derived and both the fracture mechanics criterion as well as the strength criterion are put forward to predict the crack spacing of reinforced concrete members. The influence of concrete strength to the crack spacing is also well explained by this method. Data analysis of classical test results implies a proof for employing fracture mechanics criterion instead of the strength criterion.
\end{abstract}

\section{INTRODUCTION}

Crack spacing of reinforced concrete is one of the most important problems that indicate the damage and performance of reinforced concrete structures. In Bazant's crack band theory [1], the width of fracture process zone is proposed as the element size for modelling plain concrete. For reinforced concrete, the exact application of crack band theory employs the crack spacing as kernel input quantity for determining softening modulus of concrete, thus, a precise application of crack band theory inherently requires the crack spacing of reinforced concrete. However, a unified formula for average crack spacing of reinforced concrete member under tension and flexure is still not widely accepted.

There were historically two major kinds of hypotheses for crack spacing: the bond-slip method and the no-slip method. The bond-slip method assumes that the crack formation 
requires the maximum stress in concrete to be equals to the tensile strength of concrete. The bond-slip method established prior to 1943 was summarized by Watstein and Parsons [2].They found out that for old-type deformed bars without longitudinal ribs, the crack spacing was proportional to $D / \rho$ ( $D$ is rebar diameter and $\rho$ is reinforcement ratio) and that the crack width was independent of the concrete strength. Michael Chit and Arthur Kirstein [3] introduced the concept of effective concrete area into bond-slip method and improved its prediction precision for bending specimens. However, since the release of the ASTM Designation: A305 for deformations, the modern American deformed bars which possess longitudinal ribs were used worldwide. In a test series by Hognestad [4] in 1962, it is concluded that the crack width is essentially proportional to the bar diameter $\mathrm{D}$ for plain bars and old-type American deformed bars; but less dependent on $\mathrm{D}$ for modern American deformed bars. Furthermore, the bond strength of modern deformed bars and plain round bars differs by four times while the average crack spacing and the crack width differs to a relatively minor extent [5], which contradicts with the fundamental prediction of the bond-slip method. Piyasena et al [6-7] employed two-dimensional finite element method to calculate the maximum tensile stress of concrete and established semi-empirical prediction formulas for crack spacing and width of flexural members. However, the prediction results using the from Finite Element Model method were not compared to test results directly.

The no-slip method was put forward by Broms et al. [8-10]. The crack spacing and width was investigated for tensile and flexural members. The analytical and experimental investigations showed that the primary crack spacing depended mainly on the cover thickness $\mathrm{t}$ (smallest cover thickness including rebar radius) and that $D / \rho$ or $D / \rho_{\text {te }}$ ( $\rho$ te is the effective reinforcement ratio) were poor variables. The test series by Kaar [11-12] concluded from beam tests with modern deformed bars that the quantities $\sqrt[4]{A}$ were major variables, where $A=A_{\mathrm{e}} / n$ ( $A_{\mathrm{e}}$ is the effective cracking area, $n$ is the total number of bars in tension). Gergely and Lutz [13] employed statistical regression analysis to investigate 106 data points of bottom crack width and 69 data points of side crack width, the $\sqrt[3]{t_{\mathrm{b}} A}$ or $\sqrt[3]{t_{\mathrm{s}} A} /\left(1+t_{\mathrm{s}} / h_{1}\right) \quad$ were found to be the best prediction sensitive quantities for crack width. However, the crack spacing was excluded out of this investigation ( $t \mathrm{~b}$ is the bottom cover; $t_{\mathrm{s}}$ is the side cover and $h_{1}$ is the distance from neutral axis to the center of bars in tension). Oh and Kang[14] employed statistical regression analysis to investigate 129 data points of crack spacing and 747 data points of crack width, the prediction results showed good correlation with various test data. In general, the no-slip method employed data-fitting method and was empirical, the crack spacing of direct tension specimen were merely investigated and the influence of concrete strength and size effect was generally omitted.

Bažant and Oh [15] approximately analyzed the spacing and width of cracks using the energy criterion of fracture mechanics as well as the strength criterion. The formation of cracks was treated by considering the entire crack to form simultaneously in one finite jump and the crack spacing was halved. This model employed the approximate stress lines method to calculate the strain energy.

It is acknowledged by currently used design methods [17-19] that with all other parameters unchanged (including maximum aggregate diameter), increasing the strength of concrete will reduce the crack width of reinforced concrete members in tension and flexure. Those design codes assumed that the crack spacing remains unchanged for different concrete strength, hence the change of crack width was totally due to the influence of tension stiffening. However, the direct tension test [16] showed the crack spacing decreased by 30-50 percent for all test series when concrete changed from C25 to C80. A recent study [20] employed short direct tension specimen and showed that making crack spacing a constant, the concrete strength had no significant effect on the observed crack width, neither close to the bar nor at the concrete surface. This literature 
indicates that the influence of concrete strength to crack width is mainly contributed by crack spacing while this effect were not explained by most existing models. This article presents a model which will automatically include the effect of concrete strength on crack spacing.

\section{ANALYTICAL DERIVATION}

\subsection{Boundary conditions}

Presently, direct tension test and bending test of beams are major approach in investigating crack spacing and crack width. In this study, the direct tension specimen is analyzed with a single reinforcement at the center. The radius of the cross section is $\mathrm{R}$ and the radius of the rebar is $r$, the crack spacing in analyses is $L$. In practice, the rectangular cross section with a given aspect ratio is most commonly employed in tests. In this condition, the inscribed circle of the cross section is recommended to be analyzed.

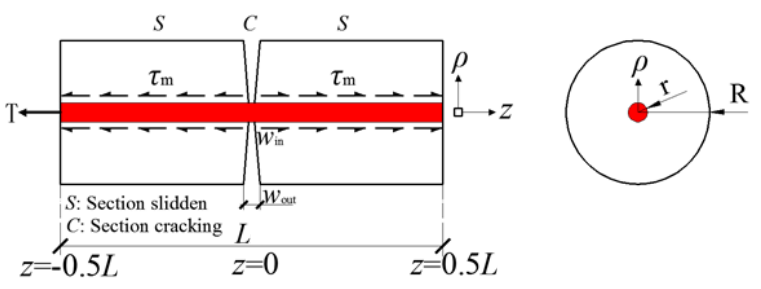

Figure 1: Boundary conditions for analysis.

Due to symmetry, only left side of Fig.1 is taken into calculating and the boundary condition is symmetric. The force boundary is taken as uniformly distributed bond stress $\tau_{\mathrm{m}}$ at the surface of rebar. Since the crack spacing is considered to be uniform at the steel stress of Over a critical value of rebar stress, the spacing of visible cracks remained approximately a constant at steel stress around $310 \mathrm{MPa}$ by Clark[21] and Michael[3], it can be assumed that the bond stress $\tau_{\mathrm{m}}$ equals the maximum bond strength between reinforcement and concrete. No force is assumed to exist between the crack section.

This problem falls into the spatial axisymmetric problem of elastic mechanics. $\mathrm{z}$ axis is defined as the axial direction, $\rho$ is defined as the radial direction and $\varphi$ is the circumferential direction as plotted in Fig.1. Only the region of $\mathrm{z}$ between $(-0.5 L, 0)$ is investigated.

\subsection{Equations for Axisymmetric problem}

The basic equilibrium condition for the axisymmetric mechanics problem is listed as following.

The radial force equilibrium equation:

$$
\frac{\partial \sigma_{\rho}}{\partial \rho}+\frac{\partial \tau_{\rho \mathrm{z}}}{\partial z}+\frac{\sigma_{\rho}-\sigma_{\varphi}}{\rho}=0
$$

The axial force equilibrium equation:

$$
\frac{\partial \sigma_{z}}{\partial z}+\frac{\partial \tau_{\rho z}}{\partial \rho}+\frac{\tau_{\rho z}}{\rho}=0
$$

The definition of strain in axisymmetric problems:

$$
\begin{gathered}
\varepsilon_{\rho}=\frac{\partial u_{\rho}}{\partial \rho} \\
\varepsilon_{\varphi}=\frac{u_{\rho}}{\rho} \\
\varepsilon_{z}=\frac{\partial \sigma_{z}}{\partial z}
\end{gathered}
$$

$$
\gamma_{\rho z}=\frac{\partial u_{\rho}}{\partial z}+\frac{\partial u_{z}}{\partial \rho}
$$

The constitutive equations:

$$
\begin{gathered}
\sigma_{\rho}=\frac{E}{1+\mu}\left(\frac{\mu}{1-2 \mu} \theta+\varepsilon_{\rho}\right) \\
\sigma_{\varphi}=\frac{E}{1+\mu}\left(\frac{\mu}{1-2 \mu} \theta+\varepsilon_{\varphi}\right) \\
\sigma_{\mathrm{z}}=\frac{E}{1+\mu}\left(\frac{\mu}{1-2 \mu} \theta+\varepsilon_{\mathrm{z}}\right) \\
\tau_{\rho \mathrm{z}}=G \gamma_{\rho \mathrm{z}} \\
\theta=\varepsilon_{\rho}+\varepsilon_{\varphi}+\varepsilon_{\mathrm{z}}
\end{gathered}
$$


The geometric boundary conditions for the symmetric section:

$$
u_{\mathrm{z}}\left(\mathrm{z}=-\frac{L}{2}\right)=0
$$

In the following derivation, the displacement boundary condition Eq.12 can only be approximately solved. It is unlikely to ensure the axial displacement at the symmetric boundary to be exactly zero due to the taylor expansion approach in 2.3.

The force boundary conditions are as following:

$$
\begin{gathered}
\sigma_{\mathrm{z}}(\mathrm{z}=0)=0 \\
\tau_{\rho \mathrm{z}}(\rho=\mathrm{R})=0 \\
\tau_{\rho \mathrm{z}}(\rho=r)=-\tau_{\mathrm{m}} \\
\sigma_{\rho}(\rho=r)=\sigma_{\rho}(\rho=R)=0
\end{gathered}
$$

The Eq.13 to Eq.15 can be exactly achieved while the Eq.16 can only be approximately achieved. However, since the radial stress component is quite small quantity with respect to the axial stress component and the shear stress, this approximation is applicable.

\subsection{Approximate solutions}

Based on the displacement method and the energy principle, the equations above can be approximately solved. The Tylor expansion of axial displacement $u_{z}$ and radial displacement $u_{\rho}$ are expanded with respect to z. Higher orders are neglected. The functions $f_{1}$ to $f_{7}$ are assumed to rely soly on the radial coordinate $\rho$.

$$
\begin{gathered}
u_{z}=f_{1}+z f_{2}+z^{2} f_{3} \\
u_{\mathrm{\rho}}=f_{4}+z f_{5}+z^{2} f_{6}+z^{3} f_{7}
\end{gathered}
$$

Substituting Eq.17 to Eq.18 into Eq.1 to Eq.11, the partial derivative equations can be converted into seven ordinary differential equations as following:

$$
\begin{aligned}
& 3\left(f_{7}^{\prime}+f_{7} / \rho\right)+(1-2 v)\left(f_{3}^{\prime \prime}+f_{3}^{\prime} / \rho\right)=0 \\
& 2\left(f_{6}^{\prime}+f_{6} / \rho\right)+(1-2 v)\left(f_{2}^{\prime \prime}+f_{2}^{\prime} / \rho\right)=0
\end{aligned}
$$

$$
\begin{aligned}
& f_{5}^{\prime}+f_{5} / \rho+2 f_{3}+(1-2 v)\left(2 f_{3}+f_{1}^{\prime \prime}+f_{1}^{\prime} / \rho\right)=0 \\
& f_{4}^{\prime \prime}+\left(f_{4} / \rho\right)^{\prime}+2 f_{2}+ \\
& (1-2 v)\left[2 f_{6}+f_{4}^{\prime \prime}+\left(f_{4} / \rho\right)^{\prime}\right]=0 \\
& f_{5}^{\prime \prime}+\left(f_{5} / \rho\right)^{\prime}+2 f_{3}+ \\
& (1-2 v)\left[6 f_{7}+f_{5}^{\prime \prime}+\left(f_{5} / \rho\right)^{\prime}\right]=0 \\
& f_{6}^{\prime \prime}+\left(f_{6} / \rho\right)^{\prime}=0
\end{aligned}
$$

The solution to the functions are as following:

$$
\begin{gathered}
f_{1}=\mathrm{C}_{13} \rho+\frac{\mathrm{C}_{14}}{\rho}+\left(\frac{-1}{1-2 v}\right) \times \\
\left\{\frac{\rho^{3}}{4}\left[2 \mathrm{C}_{11}+4(1-v) \mathrm{C}_{8}+\frac{\mathrm{C}_{7}+3(1-2 v) \mathrm{C}_{2}}{2-2 v}\right]\right. \\
\left.-\frac{\rho^{2} \ln \rho-\rho^{2}}{4}\left[\frac{\mathrm{C}_{7}+3(1-2 v) \mathrm{C}_{2}}{1-v}-(4-4 v) \mathrm{C}_{7}\right]\right\} \\
f_{2}=-\frac{\mathrm{C}_{3} \rho^{2}}{1-2 v}+\mathrm{C}_{5} \ln \rho+\mathrm{C}_{6} \\
f_{3}=\mathrm{C}_{8}-3 \mathrm{C}_{2} \ln \rho \\
f_{4}=\mathrm{C}_{9} \rho+\frac{\mathrm{C}_{10}}{\rho}+\frac{\mathrm{C}_{3} \rho^{3}}{1-2 v} \frac{v}{2} \\
-\frac{0.5 \rho \ln \rho\left[\mathrm{C}_{5}+2(1-2 v) \mathrm{C}_{4}\right]}{2-2 v} \\
f_{5}=\mathrm{C}_{11} \rho+\frac{\mathrm{C}_{12}}{\rho}+\frac{\mathrm{C}_{1} \rho^{3}}{1-2 v} \frac{3 v}{2} \\
-\frac{\rho \ln \rho\left[\mathrm{C}_{7}+3(1-2 v) \mathrm{C}_{2}\right]}{2-2 v} \\
f_{6}=\mathrm{C}_{3} \rho+\frac{\mathrm{C}_{4}}{\rho} \\
f_{7}=\mathrm{C}_{1} \rho+\frac{\mathrm{C}_{2}}{\rho}
\end{gathered}
$$

Considering the boundary conditions Eq.14 to Eq.15, the following equations can be derived: 


$$
\begin{array}{r}
3 f_{7}(\mathrm{R})+f_{7}^{\prime}(\mathrm{R})=0 \\
3 f_{7}(\mathrm{r})+f_{7}^{\prime}(\mathrm{r})=0 \\
2 f_{6}(\mathrm{R})+f_{2}^{\prime}(\mathrm{R})=0 \\
2 f_{6}(\mathrm{r})+f_{2}^{\prime}(\mathrm{r})=0
\end{array}
$$

Eq.33 requires the coefficients to be:

$$
\begin{aligned}
\mathrm{C}_{1} & =0 \\
\mathrm{C}_{3} & =0 \\
\mathrm{C}_{7}+3 \mathrm{C}_{2} & =0 \\
\mathrm{C}_{5}+2 \mathrm{C}_{4} & =0
\end{aligned}
$$

The force equilibrium condition equation (13) requires the coefficients are:

$$
\mathrm{C}_{4}=\mathrm{C}_{5}=\mathrm{C}_{6}=\mathrm{C}_{9}=0
$$

The original derivation employing unknown coefficients are quite complicated, but the coefficients with contribution to normal stress and shear stress are limited. Through variable substitution, a simplified representation for the stress can be obtained as:

$$
\begin{gathered}
\sigma_{\mathrm{z}}=z\left[B \ln \left(\frac{\rho}{r}\right)+A\right] \\
\tau_{\mathrm{\rho z}}=C \rho \ln \left(\frac{\rho}{r}\right)+D \rho+\frac{K}{\rho}
\end{gathered}
$$

Where $A, B, \mathrm{C}, D$ and $K$ are unknown variables. Considering the force equilibrium conditions and force boundary conditions, the relations between the variables are:

$$
\begin{gathered}
B+2 C=0 \\
C+2 D+A=0 \\
C R \ln \left(\frac{R}{r}\right)+D R+\frac{K}{R}=0 \\
D r+\frac{K}{r}=-\tau_{\mathrm{m}}
\end{gathered}
$$

While four equations exists for five parameters, only one parameters within $A, B, \mathrm{C}$, $D$ and $K$ can varies and this stands for an infinitesimal number of solutions. The uncertainties in solution arise from the approximation of Eq.12 and Eq.16. In order to determine the parameters, the minimum potential energy principle with mixed variables is employed. In the derivation above, the displacement fields fit the requirements of the minimum potential energy principle and the total potential energy with mixed variables is as following:

$$
\begin{aligned}
\Pi_{\mathrm{mp}} & =\iiint_{V} A(\mathrm{e}) \mathrm{d} V-\iiint_{V} F_{i} u_{i} \mathrm{~d} V \\
& -\iint_{S_{p}} \bar{p}_{i} u_{i} d S+\iint_{S_{u}} \bar{u}_{i} p_{i} d S
\end{aligned}
$$

In Eq.42, the $\Pi_{\mathrm{mp}}$ is the potential energy with mixed variables, the $A$ is the strain energy of each volume element, $F_{\mathrm{i}}$ and $u_{\mathrm{i}}$ are external volumetric forces and the corresponding displacements. $S_{\mathrm{p}}$ is the set of force boundary and $S_{\mathrm{u}}$ is the set of displacement boundary.

Denote the strain energy of axial stress is $E_{\sigma}$, the strain energy of shear stress is $E_{\tau}$. The strain energy due to radial stress can be neglected since radial force is extremely small as compared to axial stress and shear stress. The external work done due to the uniform shear force $\tau_{\mathrm{m}}$ is $W$.

From Eq.36 to Eq.41, it can be derived that:

$$
\begin{gathered}
\frac{\partial E_{\sigma}}{\partial A}=L^{3}\left(A R^{2}-A r^{2}+2 \tau_{\mathrm{m}} r\right) \\
\times\left[R^{2}-r^{2}+2 R r \ln \left(\frac{R}{r}\right)\right] \\
\times\left[R^{2}-r^{2}-2 R r \ln \left(\frac{R}{r}\right)\right] \\
/ 6 \mathrm{E}\left[R^{2}-r^{2}-2 R^{2} \ln \left(\frac{R}{r}\right)\right]^{2} \\
\frac{\partial E_{\tau}}{\partial A}=\frac{(v+1) \mathrm{L}}{16 \mathrm{E}\left[R^{2}-r^{2}-2 R^{2} \ln \left(\frac{R}{r}\right)\right]^{2}} \times \\
\left\{\operatorname { l n } ( \frac { R } { r } ) \left[-12 A R^{6} r^{2}+12 \tau_{\mathrm{m}} R^{6} r-144 \tau_{\mathrm{m}} R^{4}\right.\right. \\
\left.+120 A R^{4} r^{4}-12 A R^{2} r^{6}+36 \tau_{\mathrm{m}} R^{2} r^{5}\right] \\
+A R^{8}-2 A R^{6} r^{2}-4 \tau_{\mathrm{m}} R^{6} r+4 \tau_{\mathrm{m}} r^{7} \\
\left.+12 \tau_{\mathrm{m}} R^{4} r^{3}+2 A R^{2} r^{6}-12 \tau_{\mathrm{m}} R^{2} r^{5}-A r^{8}\right\} \\
\frac{\partial W}{\partial A}=\frac{-L^{3} A \tau_{\mathrm{m}}}{3 \mathrm{E}} \\
\frac{\partial E_{\sigma}}{\partial A}+\frac{\partial E_{\tau}}{\partial A}-\frac{\partial W}{\partial A}=0
\end{gathered}
$$

Based on Eq.46, the approximate solution for 
$A$ can be derived based on the minimum potential energy principle with mixed variables.

While the $\mathrm{A}$ is derived, the maximum normal stress is proved to be adjacent to the reinforcement as following equation:

$$
\sigma_{\max }=-0.5 L A
$$

\subsection{Strength criterion}

The traditional strength criterion requires the crack spacing minimum crack spacing to be:

$$
\begin{gathered}
l_{\min }=\frac{f_{\mathrm{t}} A_{\mathrm{c}}}{\tau_{\mathrm{m}} \pi d}=\frac{d}{4 \rho} \frac{f_{\mathrm{t}}}{\tau_{\mathrm{m}}} \\
l_{\mathrm{m}}=1.5 l_{\min }
\end{gathered}
$$

This traditional strength criterion correspond to the perfect plasticity material and not applies to concrete. The strength criterion based on the derivation above can be formulated as:

$$
\sigma_{\text {max }}=f_{\mathrm{t}}
$$

\subsection{Fracture energy criterion}

Another approach put forward by Bažant and $\mathrm{Oh}[15]$ requires that the fracture energy of concrete equals the energy release in formation a new crack. It was recommended that the maximum crack spacing $L_{\max }$ and minimum crack spacing $L_{\min }$ are:

$$
\begin{aligned}
& L_{\text {max }}=\frac{4}{3} L_{m} \\
& L_{\text {min }}=\frac{2}{3} L_{m}
\end{aligned}
$$

Define the function $U(L)$ as the total strain energy function of the concrete with length of $L$. the total strain energy $U(L)$ is obtained from the derivation above:

$$
U(L)=E_{\sigma}(L)+E_{\tau}(L)
$$

The fracture energy criterion for a microcrack to grow into visible crack requires the energy release of formation a new crack equals the fracture energy of concrete:

$$
U\left(\frac{4}{3} L_{\mathrm{m}}\right)-2 U\left(\frac{2}{3} L_{\mathrm{m}}\right)=A_{\mathrm{c}} G_{\mathrm{F}}
$$

\section{DISCUSSION}

The strength criterion as well as the fracture energy criterion are two approaches to predict the crack spacing of reinforced concrete. There are mainly two reasons for employing fracture energy criterion instead of strength criterion as following.

\subsection{The influence of concrete strength}

The influence of concrete strength on the crack spacing has been controversial. Traditional investigations by Hognestad [4] and Michael [3] was conducted in 1960s and the compressive strength of concrete varies from $14.5 \mathrm{Mpa}$ to $48.5 \mathrm{Mpa}$, their flexural tests shows no obvious influence of concrete strength on the average crack spacing. A recent study conducted by Woo and Lee [16] employed concrete strength varying from $24.8 \mathrm{MPa}$ to $80.4 \mathrm{MPa}$, and used duplicate specimens to eliminate experimental error. A clear relationship between crack spacing and concrete compressive strength is found out for all test series. The average crack spacing $L_{\mathrm{m}}-$ c/D plot by Woo and Lee is as shown in Fig.2. The results from duplicate tests are averaged to give a single point. The prediction results by formulas of Broms [8] and Model Code 1990 [19] predicts no obvious effect due to the concrete strength.

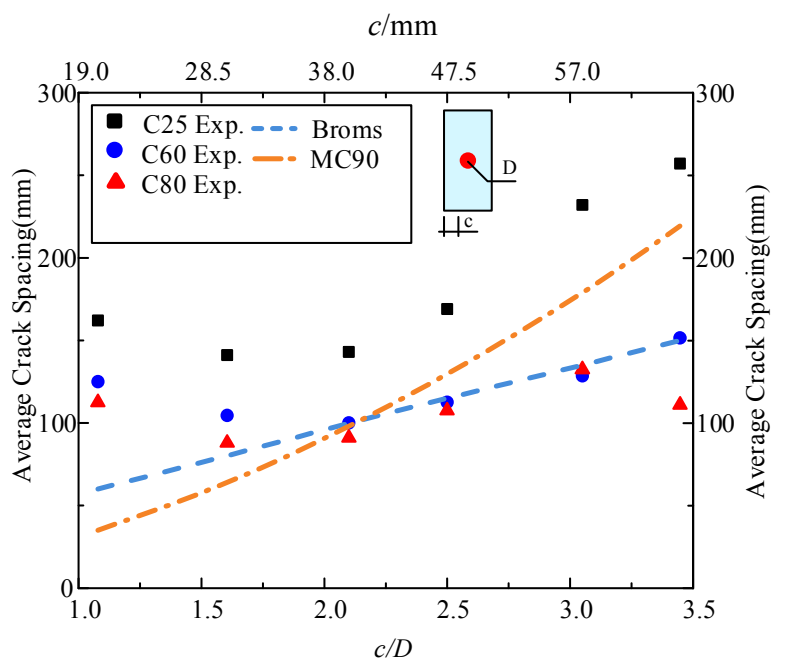

Figure 2: $L_{\mathrm{m}}-c / D$ plot by Woo and Lee [16] 
Assume the bond strength is proportional to the tensile strength of concrete:

$$
\alpha=\tau / f_{\mathrm{t}}
$$

The strength criterion predicts no effect of concrete strength since the tensile strength of concrete $f_{\mathrm{t}}$ cancels out with the bond strength $\tau_{\mathrm{m}}$. In fracture energy criterion, however, the results can be obtained from dimensional analysis.

By dimensional analysis, the strain energy of the direct tension member can be decomposed into material properties and geometric properties respectively:

$$
U(L)=\frac{\tau_{\mathrm{m}}^{2}}{E_{\mathrm{c}}} V(L)
$$

Equate the energy release to the fracture energy of concrete:

$$
V\left(\frac{4}{3} L_{m}\right)-2 V\left(\frac{2}{3} L_{m}\right)=A_{\mathrm{c}} \frac{G_{\mathrm{F}} E_{\mathrm{c}}}{\tau_{m}^{2}}
$$

Assume the bond strength is proportional to the tensile strength of concrete:

$$
V\left(\frac{4}{3} L_{m}\right)-2 V\left(\frac{2}{3} L_{m}\right)=\frac{A_{\mathrm{c}} \alpha^{2} G_{\mathrm{F}} E_{\mathrm{c}}}{f_{\mathrm{t}}^{\prime 2}}
$$

The characteristic length of concrete as defined in Eq.60 is particularly suitable to describe the ductility and crack sensitivity of concrete:

$$
l_{\mathrm{ch}}=\frac{G_{\mathrm{F}} E_{\mathrm{c}}}{f_{\mathrm{t}}^{\prime 2}}
$$

According to Eq.59 and Eq.60:

$$
V\left(\frac{4}{3} L_{m}\right)-2 V\left(\frac{2}{3} L_{m}\right)=A_{\mathrm{c}} \alpha^{2} l_{\mathrm{ch}}
$$

Thus, the left hand side has been proved to increase monotonically with $L_{\mathrm{m}}$, while the right hand side consists of $l_{\text {ch }}$ which drops with increasing concrete strength by:

$$
l_{\mathrm{ch}}=600 a_{d} f_{c m}^{-0.3}
$$

$$
a_{d}= \begin{cases}4 & d_{\max }=8 \mathrm{~mm} \\ 6 & d_{\max }=16 \mathrm{~mm} \\ 10 & d_{\max }=32 \mathrm{~mm}\end{cases}
$$

\subsection{Size effect of crack spacing and width}

The size effect of crack spacing and crack width has not been widely acknowledged by researchers. The main reason is the lack of size effect tests of cracking behavior of reinforced concrete. The geometrical similarity is not guaranteed in existing tests for cracking of reinforced concrete. However, Kaar [11-12] investigated 44 test results of the maximum crack width and 47 test results of average crack width at the steel level for a large range of beam size. While the effective cracking area surrounding each bar $A$ satisfies: $3.0<A<50.0 \mathrm{sq}$. in. $\left(1940<A<32260 \mathrm{~mm}^{2}\right)$, the optimum fitting formula can be represented by the following equation:

$$
\begin{aligned}
& w_{\mathrm{s} \max }=0.115 \sqrt[4]{A} f_{\mathrm{s}} \times 10^{-6} \mathrm{in} \\
& w_{\mathrm{s} \max }=3.31 \sqrt[4]{A} f_{\mathrm{s}} \times 10^{-6} \mathrm{~mm} \\
& w_{\mathrm{s} \mathrm{m}}=0.077 \sqrt[4]{A} f_{\mathrm{s}} \times 10^{-6} \mathrm{in} \\
& w_{\mathrm{s} \mathrm{m}}=2.22 \sqrt[4]{A} f_{\mathrm{s}} \times 10^{-6} \mathrm{~mm}
\end{aligned}
$$

In Kaar's reports, $w_{\mathrm{m}}-A$ logarithm plot as well as $w_{\max }-A$ logarithm plot were shown and it is quite clear from the logarithm plot that the slope is $1 / 4$. Thus, the data analysis based on existing tests shows solid proof for the size effect of crack width.

The equations above are solid proof for the size effect of crack spacing. Since the average crack width as well as the maximum crack width for a given steel stress is proportional to crack spacing.

The fracture energy criterion can predict such a size effect. Another simplified explanation of this size effect law is to consider a LEFM-based formula to reduce the tensile strength of concrete in bond-slip model. In traditional bond-slip model, the crack spacing is regarded to be controlled by following 
equations:

$$
\begin{gathered}
f_{\mathrm{t}} A_{\mathrm{c}}=\frac{1}{2} \pi D \tau_{\mathrm{m}} L_{\max } \\
L_{\max }=\frac{2 f_{\mathrm{t}} A_{\mathrm{e}}}{\tau_{\mathrm{m}} \pi D} \\
L_{\mathrm{m}}=\frac{3}{4} L_{\max }=\frac{3 f_{\mathrm{t}} A_{\mathrm{e}}}{2 \tau_{\mathrm{m}} \cdot \pi D}
\end{gathered}
$$

Considering the reduction of tensile strength based on LEFM results:

$$
\begin{gathered}
f_{t} \propto 1 / \sqrt{D} \\
A_{\mathrm{e}} \propto D^{2} \\
L_{\mathrm{m}} \propto \sqrt{D}
\end{gathered}
$$

The discussion above is a simplified explanation of the reason why the fracture energy criterion would predict the size effect of $L_{\mathrm{m}} \propto \sqrt{D}$.

\section{CONLUSIONS}

In this research, an approximate solution for the axisymmetric elasticity problem is put forward based on Minimum potential energy principle with mixed variables and both the strength criterion and the fracture energy criterion are discussed to predict the crack spacing. The fracture energy criterion is more applicable since it can predict the influence of concrete strength and the size effect of crack spacing.

\section{ACKNOWLEDGEREFERENCES}

The authors gratefully acknowledge the financial support provided by the Beijing Natural Science Foundation (Grant number 8162023), and the State Key Laboratory of Structural Analysis for Industrial Equipment, Dalian University of Technology (grand number GZ15108).

\section{REFERENCES}

[1]. Bažant, Z.P., and Oh, B.H. 1983. Crack Band Theory for Fracture of Concrete.
Matériaux et construction 16: 155-177.

[2]. Watstein, D. and Parsons, D.E. 1943. Width and Spacing of Tensile Cracks in Axially Reinforced Concrete Cylinders. Journal of Research 31: 1-24.

[3]. Chi, M., and Kristein, A.F. 1958. Flexural Cracks in Reinforced Concrete Beams. Journal Proceedings 54: 865-878.

[4]. Hognestad, E. 1962. High Strength bars as Concrete Reinforcement Part 2 Control of cracking. Journal of the PCA Research Development Laboratories 5:46-62.

[5]. Base, G.D. 1966. An Investigation of the Crack Control Characteristics of Various Types of Bar in Reinforced Concrete Beams. Cement and Concrete Association 62:31-38.

[6]. Piyasena, R., Loo, Y.C., and Fragomeni, S. 2004. Factors Influencing Spacing and Width of Cracks in Reinforced Concrete; New Prediction Formulae. Advances in Structural Engineering, 7: 49-60.

[7]. Piyasena, R., Loo, Y. C., and Fragomeni, S. 2003. Determination of Crack Spacing and Crack Width in Reinforced Concrete Beams. Structural Engineering and Mechanics 15: 159-180.

[8]. Broms, B. B. 1965. Crack Width and Crack Spacing in Reinforced Concrete Members. Journal of the American Concrete Institute 62, 1237-1256.

[9]. Broms, B. B. 1965. Stress Distribution in Reinforced Concrete Members with Tension Cracks. In Journal Proceedings 9:1095-1108.

[10]. Broms, B. B. 1965. Technique for Investigation of Internal Cracks in Reinforced Concrete Members. Journal of the American Concrete Institute 62, 35-44

[11]. Kaar, P. H., and Mattock, A.H. 1963.High Strength Bars as Concrete Reinforcement Part 4 Control of Cracking. Journal of the PCA Research Development Laboratories 5:15-38.

[12]. Kaar, P. H., and H. Eivind.1965. High Strength Bars as Concrete Reinforcement Part 7 Control of Cracking. Journal of the PCA Research Development Laboratories 5:42-53.

[13]. Gergely, P., and Lutz, L.A. 1968. 
Maximum Crack Width in Reinforced Concrete Flexural Members., in Causes, Mechanism and Control of Cracking in concrete. American Concrete Institute: pp.87-117.

[14]. OH, B.H. and Kang, Y.J. 1987. New Formulas for Maximum Crack Width and Crack Spacing in Reinforced Cconcrete Flexural Members. ACI Structural Journal 84:103-112.

[15]. Bažant, Z.P., and Oh, B.H. 1983. Spacing of Cracks in Reinforced Concrete. Journal of Structural Engineering 109:2066-2085.

[16]. Lee, G. and Kim, W. 2009. Cracking and Tension Stiffening Behavior of Highstrength Concrete Tension Members Subjected to Axial Load. Advances in Structural Engineering 12: 127-137.

[17]. China. M.O.C.O., Code for Seismic Design of buildings (GB 50011-2010). 2010, China Architecture and Buildings Press: Beijing, China.

[18]. EN, B.S., 1-1. Eurocode 2: Design of Concrete Structures: Part 1-1: General Rules and Rules for Buildings. London: British Standards Institution, 2004.

[19]. Code, C.M., CEB-FIP Model Code 1990. Bulletin D'Information, 1991(203): pp. 204.

[20]. Tammo, K. and Thelandersson, S. 2009. Crack Behavior near Reinforcing Bars in Concrete Structures. ACI Struct Journal 106:259-267.

[21]. Clark, A.P. 1956. Cracking in Reinforced Concrete Flexrual Members. Jouranal Proceedings 52:851-862 